\title{
Antibacterial effect of chitosan and its derivative on Enterococcus faecalis associated with endodontic infection
}

\author{
NAN WANG ${ }^{1,2}$, YANJING JI ${ }^{1,2}$, YANLI ZHU ${ }^{1,2}$, XINYI WU $^{2}$, LI MEI $^{2}$, \\ HONGZHE ZHANG ${ }^{1,2}$, JING DENG ${ }^{1,2}$ and SHUAI WANG ${ }^{1,2}$ \\ ${ }^{1}$ Department of Stomatology, The Affiliated Hospital of Qingdao University; \\ ${ }^{2}$ Department of Operative Dentistry and Endodontics, School of Stomatology, \\ Qingdao University, Qingdao, Shandong 266003, P.R. China
}

Received September 14, 2019; Accepted March 10, 2020

DOI: $10.3892 /$ etm.2020.8656

\begin{abstract}
Chitosan and its derivatives have been increasingly used for bacteriostasis. To date, the effect of chitosan and $\mathrm{N}$-(2-hydroxyl) propyl-3-trimethyl ammonium chitosan chloride (HTCC) on Enterococcus faecalis (E.faecalis) associated with endodontic infection has remained to be determined. Chitosan and HTCC were serially diluted with double-distilled water (DDW) or PBS at concentrations of 20-2,500 $\mu \mathrm{g} / \mathrm{ml}$. Various strains of E.faecalis (American Type Tissue Collection no. 29212, as well as isolated strains P25RC and P52Sa) in plankton were adjusted to an optical density at $600 \mathrm{~nm}$ of 0.10 and treated with chitosan or HTCC. A colony-forming unit assay was used to determine the concentration of residual bacteria after treatment. Furthermore, E. faecalis biofilms were cultured on coverslips and treated with chitosan or HTCC. The coverslips were rinsed, stained using Live/dead ${ }^{\circledR}$ BacLight $^{\mathrm{TM}}$ bacterial viability kit and observed under an inverted fluorescence microscope. In addition, biofilms on dentine blocks were prepared and observed under a scanning electron microscope. MC3T3-E1 pre-osteoblasts were seeded on 96-well plates and treated with chitosan or HTCC at various concentrations. The cytotoxicity of chitosan and HTCC on MC3T3-E1 pre-osteoblasts was detected using a Cell Counting Kit-8 assay after 24, 48 and $72 \mathrm{~h}$ of treatment. The results revealed that the final minimum bactericidal concentrations (MBC) of chitosan and HTCC dissolved in DDW were 70 and $140 \mu \mathrm{g} / \mathrm{ml}$, respectively. Chitosan and HTCC in DDW exerted a significantly greater antibacterial effect as compared with that in PBS $(\mathrm{P}<0.05)$. At the MBC, chitosan and HTCC in DDW, but particularly chitosan, had a significant antibacterial effect on E. faecalis
\end{abstract}

Correspondence to: Dr Shuai Wang or Professor Jing Deng, Department of Stomatology, The Affiliated Hospital of Qingdao University, 16 Jiangsu Road, Qingdao, Shandong 266003, P.R. China E-mail: wangshuai0920@sina.com

E-mail: dengjing3333@126.com

Key words: chitosan, quaternary chitosan, Enterococcus faecalis, antimicrobial mechanism, bacterial biofilm, root canal disinfection biofilm. Chitosan exhibited no cytotoxicity to MC3T3-E1 pre-osteoblasts at a concentration of $<625 \mu \mathrm{g} / \mathrm{ml}$, while HTCC inhibited the proliferation of the cells in the concentration range of 39-10,000 $\mu \mathrm{g} / \mathrm{ml}$. In conclusion, chitosan and HTCC exhibited prominent antibacterial properties on $E$. faecalis in the planktonic state and as a biofilm via charge interaction, indicating their potential for application in root canal disinfection and fillings.

\section{Introduction}

Chitosan, which is composed of a linear copolymer compromising $\beta$-1,4-linked 2-amino-2-deoxy- $\beta$-D-glucose and units of $N$-acetyl-D-glucosamine $(1,2)$, is derived from chitin after alkaline deacetylation. Chitosan possesses a number of biological properties, including antimicrobial, antifungal, biodegradable and biocompatible properties. There is a clinical demand for these properties in numerous fields, including pharmaceutical drug delivery (3), tissue engineering (4), implants (5), genetic engineering (6), vaccine adjuvants (7) and wound healing (8).

When chitosan is dissolved in acidic medium, the amino groups of C-2 may be protonated to carry cations and then interact with negative charges. This property is associated with its antibacterial ability. When interacting with negative charges of cell membranes, amino groups disrupt the membrane structure and induce microbial death $(9,10)$. However, chitosan cannot be dissolved in neutral aqueous solutions or organic solvents, which limits its application in certain fields. In addition, the antibacterial effect has been indicated to be weaker in neutral environments (10). Therefore, modification of chitosan to enhance its solubility while maintaining its antibacterial ability may allow for it to be applied in a broader range of conditions.

$N$-[(2-hydroxy-3-trimethylammonium) propyl] chitosan chloride (HTCC) derivatives, synthesized using an alkylation reaction to introduce chains to obtain quaternary ammonium groups, have a degree of substitution of $10-98 \%$ (11). As compared with chitosan, this derivative has a better solubility that may be dissolved in neutral or alkaline solutions. Furthermore, HTCC possesses the ability to resist bacteria and fungi $(11,12)$. 
Most endodontic and periapical diseases are attributed to infection with microbes and the principal aim of treatment is to eliminate these pathogens. Root canal therapy is currently the major treatment method for endodontic and periapical diseases. However, based on aseptic conditions, the success rate of this treatment ranges from 70 to $95 \%$ (13). One of the prime reasons for endodontic failure is persistent infection in the root canal (14), which troubles patients with chronic bone defect. The composition of microbial species in filled root canals, where Enterococcus faecalis is commonly detected, is limited (15).

Enterococcus faecalis is gram-positive and capable of growing in anaerobic or aerobic environments. Under the microscope, it may be observed that E. faecalis exist on their own, in pairs or in chains, and they are abundant in human intestines. E. faecalis has been isolated from primary and persistent endodontic infections. In asymptomatic primary endodontic infections, the positive rate of E. faecalis ranged from 4 to $40 \%$, with a prevalence in the persistent lesions of $24-77 \%(16,17)$. Furthermore, as compared with untreated chronic apical periodontitis, E. faecalis was more correlated with persistent root canal infection (18).

E. faecalis may survive non-culturable conditions. It has been reported that $E$. faecalis that was inoculated in filled root canals in vitro maintained viability for a year without nutrients (19). E. faecalis may invade dentinal tubules and form biofilms, which endow them with more viability and virulence. Biofilms are environmental adaptations of E. faecalis that protect and assist microorganisms against harsh environments and antibiotics, and allows for higher internal environment stability and viability (20).

Chitosan and quaternary chitosan have broad-spectrum antibacterial properties $(21,22)$, but to date, only few studies have investigated the effect of chitosan and quaternary chitosan, particularly HTCC, on E. faecalis strains associated with endodontic infection. The aim of the present study was to explore the efficiency of chitosan and HTCC in resisting three strains of E. faecalis in the planktonic state and bacterial biofilms. The antibacterial effect of chitosan and HTCC in double-distilled water (DDW) and PBS on E. faecalis was explored and analyzed, respectively. Both DDW and PBS are common solvents used in root canal irrigations $(23,24)$. A Cell Counting Kit-8 (CCK-8) cytotoxicity assay was performed to evaluate the biocompatibility of chitosan and HTCC at various concentrations.

\section{Materials and methods}

Preparation of drugs at different concentrations. HTCC (YJ201854; Cool Chemistry) was dissolved in DDW and PBS (P1010; Beijing Solarbio Science \& Technology Co. Ltd.) and the concentration of the stock solution was $10,000 \mu \mathrm{g} / \mathrm{ml}$. Chitosan (molecular weight, $150 \mathrm{kDa}$; substitution degree, 85\%; Laizhou Haili Biological Products Co. Ltd.) was dissolved in $1 \%(\mathrm{v} / \mathrm{v})$ acetic acid (Jiangsu Qiangsheng Chemical Co. Ltd.) and the concentration of the initial stock solution was $10,000 \mu \mathrm{g} / \mathrm{ml}$. DDW and PBS were used to dilute the chitosan and HTCC solution. The double dilution method was used to prepare a series of chitosan and HTCC solutions with different concentrations, namely 2,500, 1,250, 625, 313, 156, 78, 39 and
$20 \mu \mathrm{g} / \mathrm{ml}$. All of these solutions were divided into two groups according to the solvents; the DDW and PBS groups. The positive control group was $2 \%(\mathrm{v} / \mathrm{v})$ sodium hypochlorite $(\mathrm{NaClO}$; Tianjin Beichen Fangzheng Chemical).

Preparation of bacteria. Three strains of E. faecalis from different sources were used in the present study: American Type Culture Collection (ATCC) 29212, P25RC and P52Sa (25-27) (provided by Professor Chengfei Zhang, Comprehensive Dental Care, Faculty of Dentistry, University of Hong Kong, Hong Kong, China). E. faecalis ATCC 29212 is a standard strain, while E. faecalis $\mathrm{P} 25 \mathrm{RC}$ and E. faecalis $\mathrm{P} 52 \mathrm{Sa}$ were isolated from the root canals and saliva of two patients (female; age, 18 years) with refractory periapical periodontitis in June and September 2009, respectively, at The Hospital of Stomatology, Peking University (Beijing, China). The participants of the study all provided written informed consent. This study was approved by the Medical Ethics Committee of the Affiliated Hospital of Qingdao University (Qingdao, China).

Three strains of E. faecalis (ATCC 29212, P25RC and $\mathrm{P} 52 \mathrm{Sa})$ were inoculated on solid brain heart infusion (BHI) medium containing $1.5 \%$ (w/v) agar (cat. no. A8190; Beijing Solarbio Science \& Technology Co. Ltd.) and 3.85\% (w/v) BHI powder (cat. no. A0360; Beijing Solarbio Science \& Technology Co. Ltd.), and cultured anaerobically at $37^{\circ} \mathrm{C}$ for $24 \mathrm{~h}$. One colony in BHI medium was then randomly collected, suspended in BHI broth and incubated under anaerobic conditions overnight at $37^{\circ} \mathrm{C}$. The bacterial suspension was adjusted to an optical density at $600 \mathrm{~nm}\left(\mathrm{OD}_{600}\right)$ of 0.10 using a BioPhotometer plus (Eppendorf). This was equal to a McFarland standard of 0.5 , where the concentration of E. faecalis was $7.5 \times 10^{7} / \mathrm{ml}$.

Colony-forming unit (CFU) assay. The volume ratio of experimental solution to bacterial suspension was 9:1 per well in 96-well plates (cat. no. 3599; Corning Inc.). The final drug concentrations were 2,250, 1,125, 563, 282, 140, 70,35 and $18 \mu \mathrm{g} / \mathrm{ml}$. The group with the concentration of $0 \mu \mathrm{g} / \mathrm{ml}$ contained DDW or PBS alone, without any drugs. The different antibacterial effects of chitosan or HTCC in DDW or PBS as the solvent was compared at the same concentrations, with the PBS group used as the control. These 96-well plates were cultivated under anaerobic conditions at $37^{\circ} \mathrm{C}$ for $24 \mathrm{~h}$. Following incubation, the solution in each well was 10-fold diluted at the appropriate concentration and plated on the BHI medium supplemented with $1.5 \%(\mathrm{w} / \mathrm{v})$ agar cultured overnight anaerobically at $37^{\circ} \mathrm{C}$. Colonies on plates were counted to calculate the bacterial concentration in each well. The residual bacterial concentrations were compared pairwise to the different antibacterial effects of chitosan or HTCC in DDW or PBS using the independent-samples t-test. The experiment was performed in triplicate and repeated three times independently.

Calculation of the inhibition rate (IR). To evaluate the capacity of bacteriostasis at different concentrations, the IR values of each concentration gradient were calculated to confirm the minimum bactericidal concentration (MBC). In this experiment, the $0 \mu \mathrm{g} / \mathrm{ml}$ group was the control group. The mean CFU $\left(10^{6} / \mathrm{ml}\right)$ was used in the following formula: 
IR value $=\left(\mathrm{CFU}_{0 \mu \mathrm{g} / \mathrm{ml}}-\mathrm{CFU}_{\mathrm{N} \mu \mathrm{g} / \mathrm{m})}\right) / \mathrm{CFU}_{0 \mu \mathrm{g} / \mathrm{ml}} \times 100 \%(\mathrm{~N}=2,250$ $1,125,563,282,140,70,35$ and 18).

Antibacterial effect on biofilm under inverted fluorescent microscopy. The concentration of the bacterial suspension of E. faecalis $\mathrm{P} 25 \mathrm{RC}$ was adjusted to $\mathrm{OD}_{600}=0.10$. The uncoated coverslips (18x18 mm; Sail Brand) were put into 6-well plates (cat. no. 3516; Corning Inc.) and $2 \mathrm{ml}$ bacterial suspension was added to each well for culturing biofilms. The medium was changed every other day. After constant culture for 7 days, coverslips were randomly selected for staining and the formation of bacterial biofilm was detected. The coverslips covered with bacterial biofilms were divided into 7 groups: i) $78 \mu \mathrm{g} / \mathrm{ml}$ chitosan solution diluted in PBS; ii) $156 \mu \mathrm{g} / \mathrm{ml}$ of HTCC solution diluted in PBS; iii) PBS solution; iv) $78 \mu \mathrm{g} / \mathrm{ml}$ of chitosan solution diluted in DDW; v) $156 \mu \mathrm{g} / \mathrm{ml}$ of HTCC solution diluted in DDW; vi) DDW; vii) $2 \% \mathrm{NaClO}$. The volume of the solution in each well was $2 \mathrm{ml}$ and culture was performed for $24 \mathrm{~h}$. The coverslips were then rinsed with PBS and stained with the Live-dead ${ }^{\circledR}$ Baclight $^{\text {Tix }}$ bacterial viability kit (cat. no. L-7012; Thermo Fisher Scientific, Inc.). The volume ratio of propidium iodide/SYTO 9/PBS was 1.5:1.5:1,000 and incubation was performed for $15 \mathrm{~min}$ in the dark. Once the residual dye was rinsed out, the bacterial biofilms on coverslips were observed using an inverted fluorescent microscope (magnification, x200; Olympus IX53, Olympus Corp.). Images were processed with Image J software (version 1.48; National Institutes of Health) and quantitative data on the expression of green and red fluorescence were obtained. IR was used to compare the different antibacterial effects of experimental solutions on biofilm. The experiment was performed in triplicate and repeated three times independently. The IR was calculated using the following formula: IR value=mean red fluorescence/(mean red fluorescence + mean green fluorescence) $\times 100 \%$.

Biofilm on dentine observation by scanning electron microscopy (SEM). Teeth were extracted from 3 healthy volunteers (sex, 2 female and 1 male; age range, 18-30 years) at the Affiliated Hospital of Qingdao University (Qingdao, China) in December 2019. The third permanent molars were enrolled in the study and the written informed consents were provided. Dentine blocks $(5 \times 5 \times 1 \mathrm{~mm})$ were sliced from the third permanent molars. Following autoclave sterilization $\left(121^{\circ} \mathrm{C} ; 20 \mathrm{~min}\right)$, they were immersed in bacterial solution of the E. faecalis P25RC strain $\left(\mathrm{OD}_{600}=0.10\right)$. These dentine blocks were cultured for 7 days and the old medium was changed by fresh BHI medium every other day. After rinsing the surface with DDW, they were divided into 4 groups and placed in DDW, $78 \mu \mathrm{g} / \mathrm{ml}$ chitosan (dissolved in DDW), $156 \mu \mathrm{g} / \mathrm{ml} \mathrm{HTCC}$ (dissolved in DDW) and 2\% $\mathrm{NaClO}$ (diluted in DDW) for $24 \mathrm{~h}$. The total volume of the solutions was $2 \mathrm{ml}$. After rinsing with PBS, the dentine blocks were fixed with $2.5 \%$ glutaraldehyde $\left(2 \mathrm{~h} ; 4^{\circ} \mathrm{C}\right)$ and observed under SEM (Tescan China, Ltd.). The experiment was performed in triplicate and repeated three times independently.

Cell proliferation-inhibition test. MC3T3-E1 pre-osteoblasts (ATCC) were seeded into 96-well plates at $3 \times 10^{3}$ cells per well and cultured in $\alpha$-Minimum Essential Medium ( $\alpha$ MEM; Beijing Solarbio Science \& Technology Co. Ltd.) supplemented with $10 \%(\mathrm{v} / \mathrm{v})$ fetal bovine serum (Hangzhou Sijiqing Biological
Engineering Materials Co. Ltd.) and 1\% (v/v) penicillin/streptomycin (Beijing Solarbio Science \& Technology Co. Ltd.) for $24 \mathrm{~h}$. After removing the medium, $100 \mu \mathrm{l}$ chitosan and HTCC solution at various concentrations were added in 96-well plates, including 10,000, 5,000, 2,500, 1,250, 625, 31, 156, 78 and $39 \mu \mathrm{g} / \mathrm{ml}$. These solutions were diluted with cell culture medium. The control group was cell culture medium without drugs and the blank group was cell culture medium without any cells and drugs. After 24, 48 and 72 h, CCK-8 reagent (10\%; cat. no. HY-K0301; MedChemExpress) with $\alpha$ MEM was added following the removal of residual solution and then incubated in the dark for $2 \mathrm{~h}$. The absorbance (A) value $\left(\mathrm{OD}_{450}\right)$ of each well was detected using a microplate reader (Multiskan MK3; Thermo Fisher Scientific, Inc.) and the mean A values of each group were used to calculate the proliferation-IR (PIR) of MC3T3-E1 pre-osteoblasts. The experiment was performed in duplicate and repeated three times independently. The PIR was calculated as follows: $\mathrm{PIR}=\left(\mathrm{OD}_{450}\right.$ experimental group $-\mathrm{OD}_{450}$ blank group $) /\left(\mathrm{OD}_{450}\right.$ normal medium $\left.-\mathrm{OD}_{450 \text { blank group }}\right) \times 100 \%$, where the normal medium represents cell medium without any other solutions.

Statistical analysis. Data analysis was performed using SPSS version 21 (IBM Corp.). The results were expressed by the mean \pm standard deviation. The independent-samples t-test was applied. $\mathrm{P}<0.05$ was considered to indicate a statistically significant difference. All experiments were performed in triplicate and repeated three times independently.

\section{Results}

Antibacterial effects of chitosan. The antibacterial effect of chitosan in DDW or PBS was enhanced as the concentration increased. The MBC of chitosan in DDW on the three strains was $70 \mu \mathrm{g} / \mathrm{ml}$, which was lower than the MBC of $282 \mu \mathrm{g} / \mathrm{ml}$ for chitosan in PBS (Fig. 1D-F). The IR of the positive control group $(2 \% \mathrm{NaClO})$ was $100 \%$ (data not shown).

The results of the CFU $\left(10^{6} / \mathrm{ml}\right)$ assay suggested that under most conditions, the antibacterial effect of chitosan in DDW was greater than that in PBS at the same concentration $(\mathrm{P}<0.05$; Fig. 1A-C).

Antibacterial effects of HTCC. The results regarding the inhibitory effects of HTCC are presented in Fig. 2. The MBC of HTCC in DDW was $140 \mu \mathrm{g} / \mathrm{ml}$ on the three strains (Fig. 2D-F). The minimum inhibitory concentration (MIC) for E. faecalis $\mathrm{P} 25 \mathrm{RC}$ was $18 \mu \mathrm{g} / \mathrm{ml}$, while that for the other two strains was outside the gradient concentration in this experiment (Fig. 2D). Furthermore, it was clearly demonstrated that, as compared with the negative control, the bacterial concentrations were significantly increased when the concentration of HTCC was below the MIC.

It was not possible to determine the definite bactericidal concentration of HTCC in PBS in the experimental ranges. The maximum IRs of E. faecalis strains P25RC, P52Sa and ATCC 29212 were $92.79,96.34$ and $91.19 \%$, respectively. The final MIC of E. faecalis P25RC in PBS was $70 \mu \mathrm{g} / \mathrm{ml}$ (Fig. 2D) and the CFU $\left(10^{6} / \mathrm{ml}\right)$ of concentrations below the MIC were all higher than the negative control groups. The antibacterial effect of HTCC dissolved in PBS or DDW on three strains of E. faecalis was concentration-dependent (Fig. 2). 
A

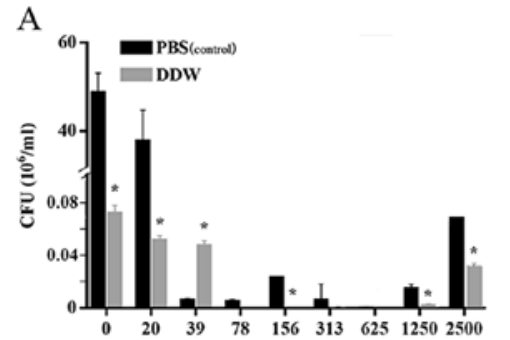

D

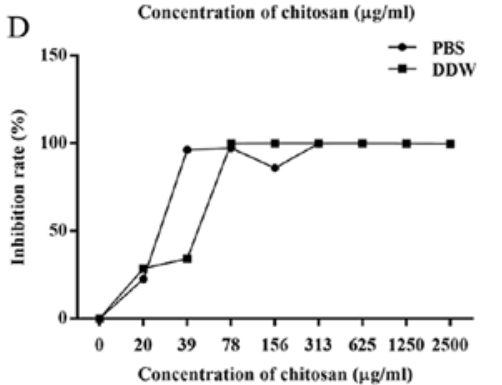

Concentration of chitosan $(\mu \mathrm{g} / \mathrm{ml})$

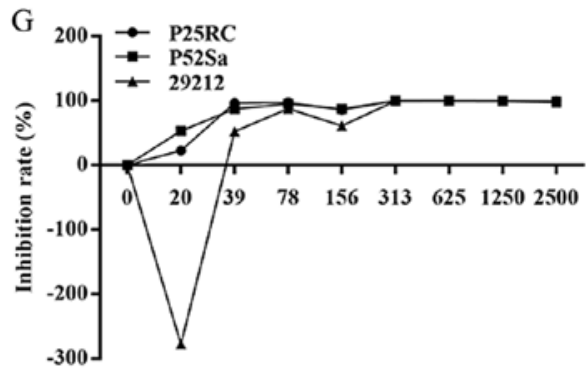

Concentration of chitosan in PBS $(\mu \mathrm{g} / \mathrm{ml})$
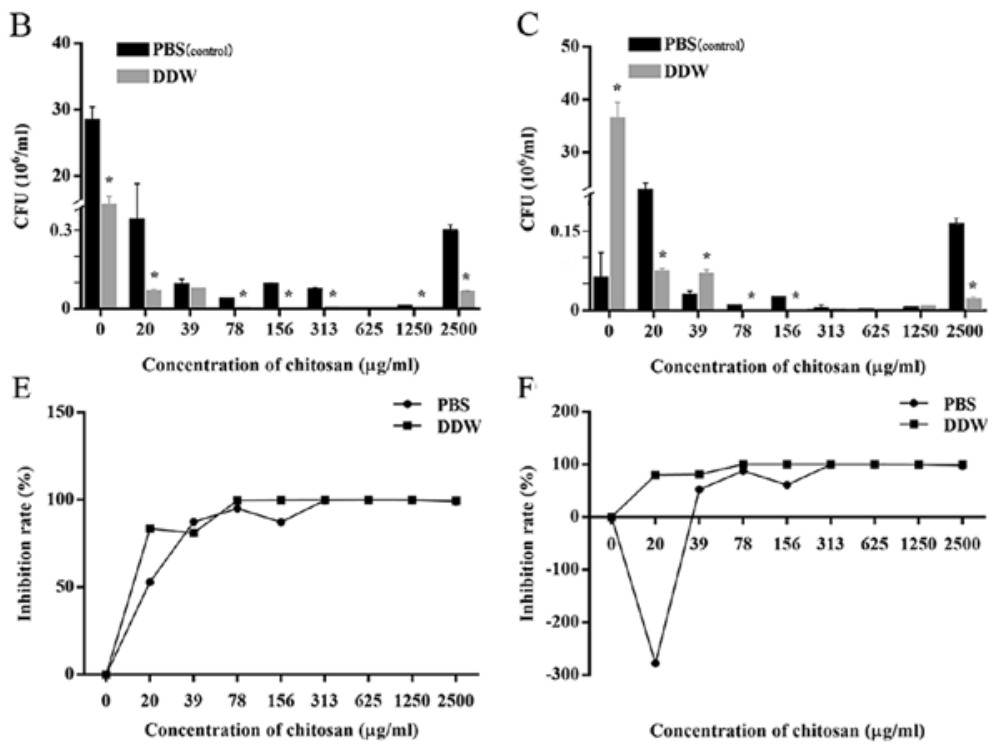

F

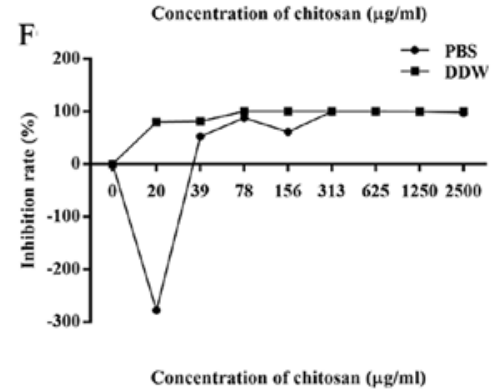

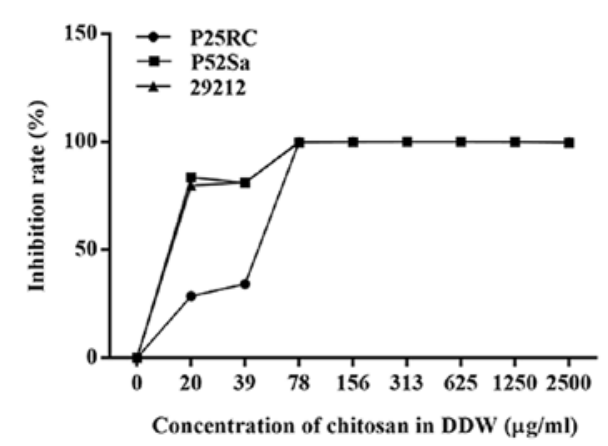

Figure 1. Chitosan in PBS and DDW exerts an inhibitory effect on E. faecalis. A CFU (10 $/ \mathrm{ml})$ assay was used to evaluate the different antibacterial effects in the PBS and DDW solvents. E. faecalis strains (A) P25RC, (B) P52Sa and (C) ATCC 29212. * $<<0.05$ vs. PBS. The inhibition rate (\%) represented the antibacterial effect of the gradient concentrations. E. faecalis strains (D) P25RC, (E) P52Sa and (F) ATCC 29212. (G) Inhibition rate (\%) of chitosan on the three strains of E.faecalis in PBS and DDW. DDW, double-distilled water; E. faecalis, Enterococcus faecalis; CFU, colony-forming unit.

To compare the antibacterial effect of HTCC in different solvents, the CFU $\left(10^{6} / \mathrm{ml}\right)$ assay indicated that, in most conditions, there were statistically significant differences between HTCC in PBS and DDW at the same concentrations $(\mathrm{P}<0.05$; Fig. 2A-C). It was indicated that the number of CFUs in the presence of HTCC in DDW was generally lower than that in PBS. Furthermore, the IR curve of HTCC in DDW on all E. faecalis strains was almost higher compared with that in PBS, which all meant the antibacterial effect of HTCC in DDW was greater compared with that dissolved in PBS. (Fig. 2D-F).

In addition, the resistance of the three strains of bacteria to chitosan and HTCC were presented in Figs. 1G and 2G, where lower IR curves indicate greater bacterial resistance to chitosan or HTCC. Prior to reaching MBC, the IR curves of E. faecalis $\mathrm{P} 25 \mathrm{RC}$ were generally lower compared with those of the other strains, apart from those for chitosan in PBS. This finding suggest that the P25RC strain showed the greatest resistance to chitosan and HTCC among the three strains.

Effect on the viability of the bacterial biofilm using fluorescence microscopy. Stained live and dead bacteria emitted green and red fluorescence, respectively. According to the IR, $2 \% \mathrm{NaClO}$ exerted the greatest bactericidal effect among the 7 groups with the IR of $97.80 \%$. The IR of group 4 was $94.00 \%$, indicating that the antibacterial effect of $78 \mu \mathrm{g} / \mathrm{ml}$ chitosan in
DDW almost reached that of $2 \% \mathrm{NaClO}$. Group $5(156 \mu \mathrm{g} / \mathrm{ml}$ HTCC in DDW) had an IR of $79.56 \%$ and the values of the other groups were far below those of these groups (Fig. 3).

Effect on biofilm on dentine surface. The effect of the treatments on biofilm on dentine blocks was observed by SEM (Fig. 4). Except for the $2 \% \mathrm{NaClO}$ group (Fig. 4A), $78 \mu \mathrm{g} / \mathrm{ml}$ chitosan in DDW had the best effect on biofilms on dentine blocks (Fig. 4C). It was observed that most of the cells were killed and rinsed away, and a minority remained together with debris. As compared with the DDW group, HTCC solution was also able to kill part of the bacteria (Fig. 4D). The whole structure of the cells on the biofilm was disrupted with membranolysis following treatment with chitosan or HTCC (Fig. 4E and F) and the dentine surface in the DDW group was contaminated by more microorganisms (Fig. 4B).

Cell proliferation-inhibition test. According to the CCK-8 assay performed at $24 \mathrm{~h}$ of incubation, the chitosan solution exhibited superior biocompatibility and even promoted cell proliferation at $<625 \mu \mathrm{g} / \mathrm{ml}$ (Fig. 5). In particular, the cell proliferation was stimulated by up to $200 \%$ (Fig. 5A). However, HTCC exhibited higher toxicity than chitosan and only the $39 \mu \mathrm{g} / \mathrm{ml}$ concentration had relatively lower cytotoxicity than the other concentrations of HTCC. 

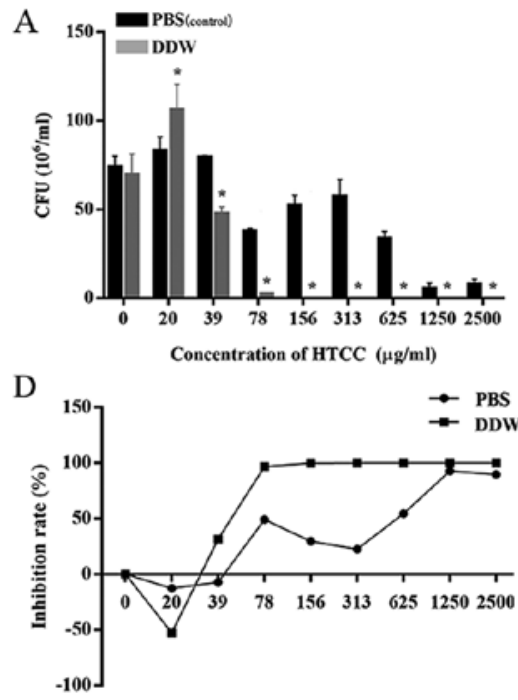

Concentration of HTCC $(\mu \mathrm{g} / \mathrm{ml})$

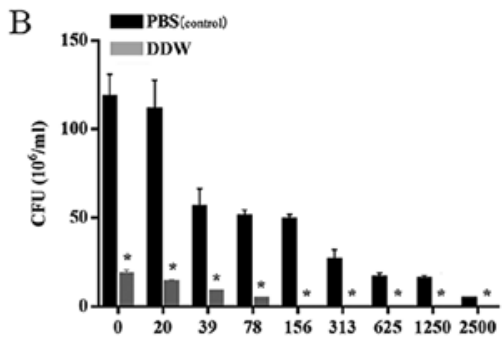

Concentration of HTCC $(\mu \mathrm{g} / \mathrm{ml})$

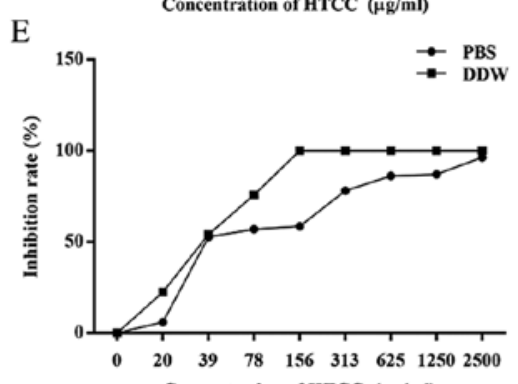

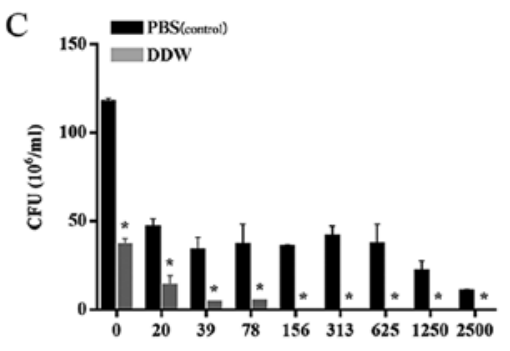

F

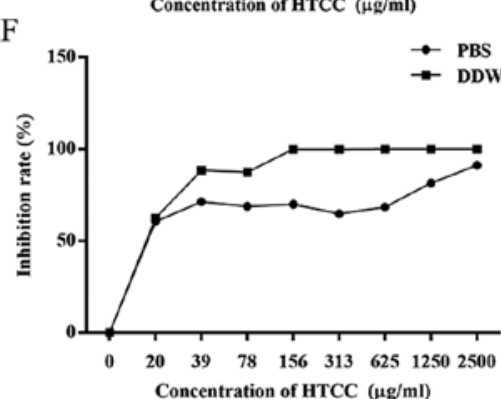

$$
\text { G }
$$

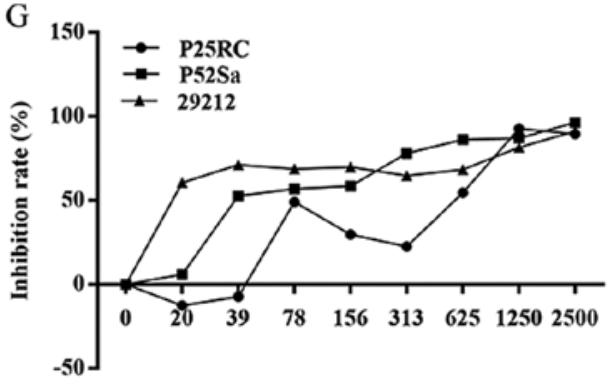

Concentration of HTCC in PBS $(\mu \mathrm{g} / \mathrm{ml})$

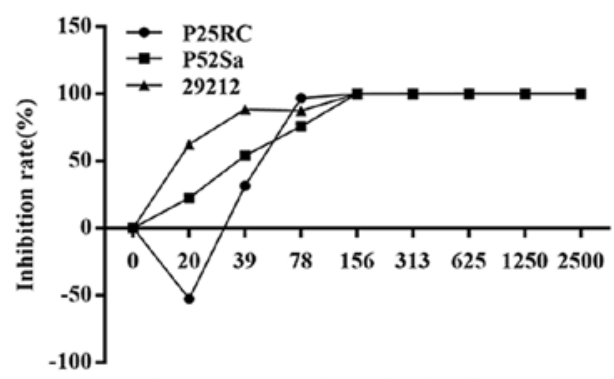

Concentration of HTCC in DDW $(\mu \mathrm{g} / \mathrm{ml})$

Figure 2. HTCC in PBS and DDW exerts an inhibitory effect on E. faecalis. CFU $\left(10^{6} / \mathrm{ml}\right)$ assay was used to evaluate the different antibacterial effects in the PBS and DDW solvents. E. faecalis strains (A) P25RC, (B) P52Sa and (C) ATCC 29212 strains. ${ }^{*}<<0.05$ vs. PBS. The inhibition rate (\%) represented the antibacterial effect among gradient concentrations. E. faecalis strains (D) P25RC, (E) P52Sa and (F) ATCC 29212. (G) Inhibition rate (\%) of HTCC on the three strains of E. faecalis in PBS and DDW. HTCC, $N$-(2-hydroxyl) propyl-3-trimethyl ammonium chitosan chloride; DDW, double-distilled water; E. faecalis, Enterococcus faecalis; CFU, colony-forming unit.

\section{Discussion}

The present study indicated that chitosan and its derivative HTCC displayed excellent antibacterial properties against E. faecalis associated with endodontic infection. It has been reported that the antibacterial properties of chitosan and its derivatives are affected by certain aspects, including the degree of deacetylation, degree of substitution and molecular weight (28). However, the present study indicated that the antibacterial effects of chitosan and HTCC exhibited significant differences in different solvents. According to the CFU assay, the residual bacterial concentration in the DDW group, under most conditions, was lower than that in the PBS group at the same drug concentration. This phenomenon appeared simultaneously for chitosan and HTCC. These results indicated that the antibacterial effect was attenuated when the compounds were dissolved in PBS.

PBS is composed of $\mathrm{Na}^{+}, \mathrm{K}^{+}, \mathrm{Cl}^{-}, \mathrm{HPO}_{4}{ }^{2-}$ and $\mathrm{H}_{2} \mathrm{PO}_{4}{ }^{-}$. PBS is usually used as a buffering solution and unlike DDW, it keeps the $\mathrm{pH}$ value stable (7.2-7.4), which, in the present study, may have interfered with the antibacterial action of chitosan and HTCC. The mechanism of the antibacterial effect of chitosan is the interaction between the positive charges on amino groups of chitosan and negative charges on the bacterial surface, as well as changes in the permeability of cell membranes, which induces the rupture of bacteria (29). To obtain HTCC, quaternary ammonium groups were introduced in the chains of chitosan and the antibacterial mechanism of this derivative is similar to that of chitosan (30). It was speculated that the ions of PBS have a pivotal role in disrupting the attraction between charges of drugs and E. faecalis, suggesting that the cations of chitosan and HTCC may bind to anions in PBS and further result in less contact between the positive charges of drugs and the negative charges on the bacterial surface. Furthermore, Chung et al (31) reported that more negative charges on the cell surface of waterborne pathogens led to an enhanced interaction with chitosan. Therefore, in the present study, cations of PBS may also lead to a decline of negative charges on cell surfaces by competing with positive charges of chitosan or HTCC and reduce the probability of contact between chitosan or HTCC and pathogens, finally weakening the antibacterial properties of chitosan and HTCC. In addition, PBS contains a buffer pair, which attenuates changes in the $\mathrm{pH}$ value. This change in $\mathrm{pH}$ value due to different solvents may affect the protonation of amino groups $\left(-\mathrm{NH}_{3}{ }^{+}\right)$on $\mathrm{C}-2$ of chitosan and HTCC and further intensify the difference in the antibacterial effect in PBS and DDW. These speculations indicated that the mechanism of the antibacterial action of chitosan and HTCC 

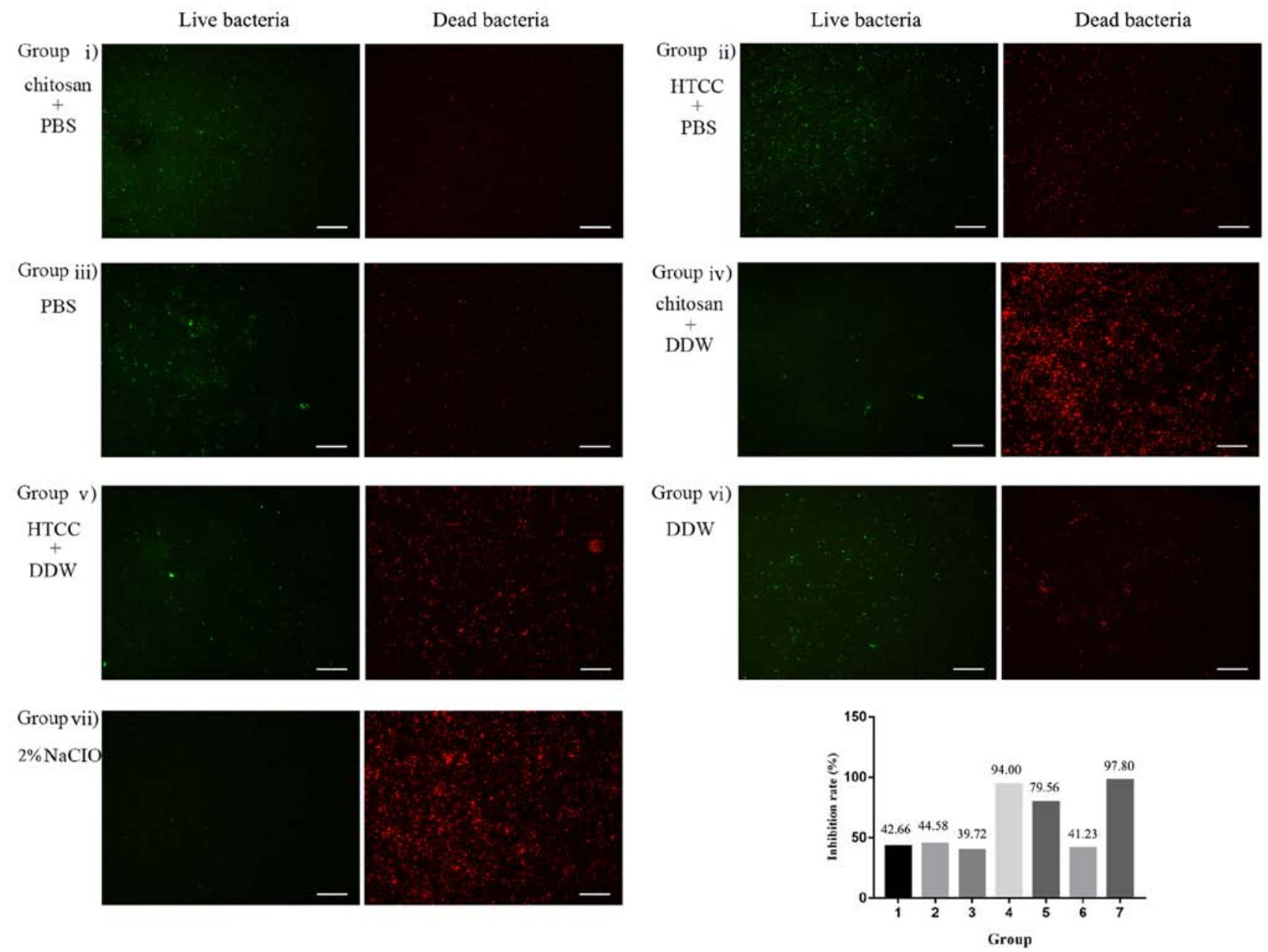

Figure 3. Bacterial biofilms of the E. faecalis P25RC strain were treated with chitosan, HTCC or $2 \% \mathrm{NaClO}$. Live bacteria emitted green fluorescence and dead bacteria emitted red fluorescence under the inverted fluorescent microscope (magnification x 200; scale bar, $50 \mu \mathrm{m}$ ). Inhibition rates (\%) of bacteria, presented as a ratio of red/(red + green) fluorescence $\mathrm{x} 100 \%$ in the biofilm in the 7 groups were presented in a bar graph. Groups were as follows: i) Chitosan dissolved in PBS at a concentration of $78 \mu \mathrm{g} / \mathrm{ml}$, ii) HTCC dissolved in PBS at a concentration of $156 \mu \mathrm{g} / \mathrm{ml}$, iii) PBS, iv) Chitosan was dissolved in DDW at a concentration of $78 \mu \mathrm{g} / \mathrm{ml}$, v) HTCC was dissolved in DDW at a concentration of $156 \mu \mathrm{g} / \mathrm{ml}$, vi) DDW, vii) $2 \%$ NaClO. E. faecalis, Enterococcus faecalis; HTCC, $N$-(2-hydroxyl) propyl-3-trimethyl ammonium chitosan chloride; DDW, double-distilled water.

may be associated with the electrostatic attraction between opposite charges.

Chitosan has been used in root canal therapy for its antibacterial effect. Ong et al (32) reported that a chitosan-propolis nanoparticle formulation partly reduced the number of bacteria in biofilm and pre-formed biofilm at a concentration of $200 \mu \mathrm{g} / \mathrm{ml}$. In addition, photo-dynamic therapy combined with $3 \mathrm{mg} / \mathrm{ml}$ chitosan performed best among various groups (33). $2 \%$ Chlorhexidine with chitosan in gel had the strongest effect against $E$. faecalis (34). This combination also performed well in the form of root canal sealer (35). However, the antibacterial effect of chitosan in a gradient concentration had not been tested in previous reports. Based on the CFU assay in the present study, it was observed that the residual bacterial concentration decreased with the increase of drug concentration in general, until the MBC was reached. In addition, a suitable concentration may be determined based on the IR. Kong et al (36) suggested that the antibacterial activity of chitosan microspheres on E. coli was proportional to the drug concentration, indicating that enhancement of the disinfecting effect of chitosan and HTCC may be achieved by adjusting the concentration.
In addition, the IR curve indicated that the value of certain low concentrations of chitosan and HTCC was negative, suggesting that at these concentrations, the residual bacterial concentration was higher than that in the control groups and that chitosan and HTCC promoted proliferation instead of inhibiting it. Chitosan has a hydrolytic susceptibility to certain types of enzymes from bacteria and may be hydrolyzed to serve as a source of energy for bacteria (37), which may lead to bacterial proliferation. According to the $\mathrm{MBC}$, the antibacterial effect of chitosan was better than that of HTCC. Ji et al (38) compared the antibacterial properties of chitosan and HTCC on periodontal pathogens, indicating that chitosan had a better antibacterial effect than HTCC, which was consistent with the results of the present study. However, HTCC is more soluble than chitosan and may be used as an alternative in root canal therapy.

The drug resistance of clinical strains isolated from the oral cavities of patients with refractory periapical periodontitis was stronger than that of the standard strains. Based on the IR curve, when the concentration of HTCC was below the $\mathrm{MBC}$, the antibacterial rate of E. faecalis $\mathrm{P} 25 \mathrm{RC}$ was the lowest among the three strains, which was the same as that 

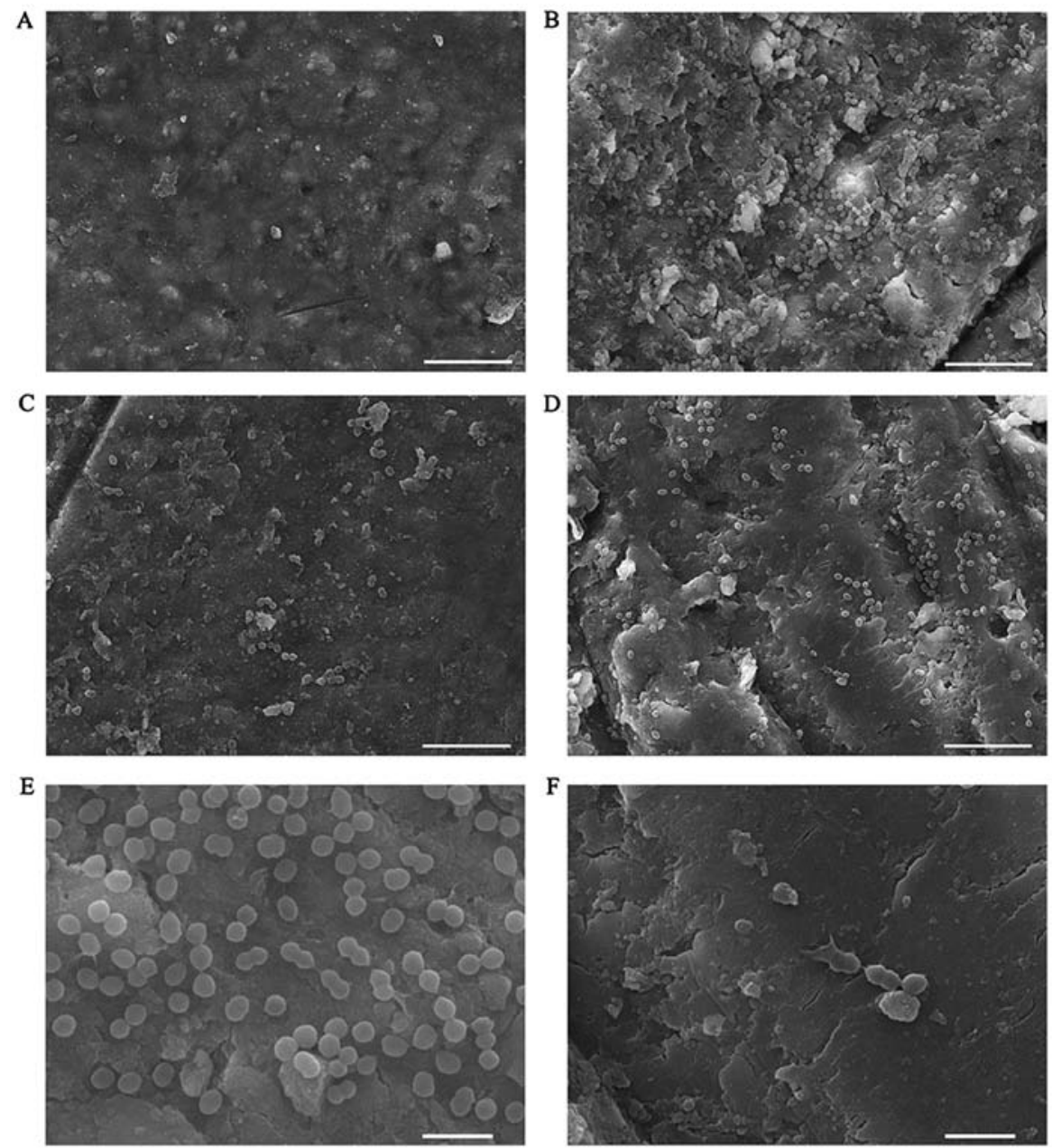

Figure 4. Bacterial biofilms of the E. faecalis $\mathrm{P} 25 \mathrm{RC}$ strain on dentine were observed by scanning electron microscopy. (A) $2 \% \mathrm{NaClO}$, (B) DDW, (C) $78 \mu \mathrm{g} / \mathrm{ml}$ chitosan in DDW, (D) $156 \mu \mathrm{g} / \mathrm{ml}$ HTCC in DDW (A-D, magnification, x5,000; scale bar, $10 \mu \mathrm{m}$ ). (E) Normal morphology of E. faecalis, (F) Rupture of membrane of E.faecalis after treatment with $156 \mu \mathrm{g} / \mathrm{ml}$ HTCC solution. (E and F, magnification, x20,000; scale bar, $2 \mu \mathrm{m}$ ). E. faecalis, Enterococcus faecalis; DDW, double-distilled water; HTCC, $N$-(2-hydroxyl) propyl-3-trimethyl ammonium chitosan chloride.
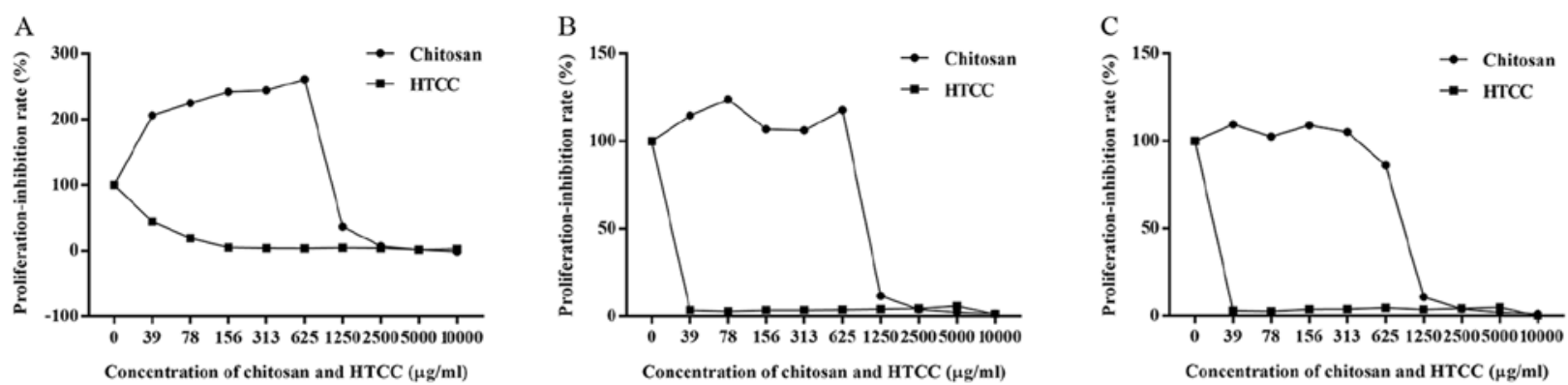

Figure 5. Proliferation-inhibition curves of chitosan and HTCC at various concentrations acting on MC3T3-E1 pre-osteoblasts for evaluating the cytotoxicity in a time-dependent manner. (A) $24 \mathrm{~h}$, (B) $48 \mathrm{~h}$ and (C) $72 \mathrm{~h}$. The untreated control group $(0 \mu \mathrm{g} / \mathrm{ml})$ was set as $100 \%$ of PIR. HTCC, $N$-(2-hydroxyl) propyl-3-trimethyl ammonium chitosan chloride.

of chitosan in DDW, indicating that $E$. faecalis P25RC may have the highest drug resistance due to having been isolated from an infectious root canal. It has been reported that the IRs in clinical strains of Candida albicans were lower than the standard strains following photodynamic therapy in biofilms (39). Therefore, E. faecalis $\mathrm{P} 25 \mathrm{RC}$ was selected and then used in the bacterial biofilm experiments to form more resistant biofilms.
In persistent infectious root canals, E. faecalis exists in the form of biofilms. According to the IR curve, $78 \mu \mathrm{g} / \mathrm{ml}$ chitosan in DDW had an IR of $94.00 \%$, which was close to the IR of $2 \% \mathrm{NaClO}(97.80 \%)$. Prior to reaching the higher cytotoxicity concentration $(>625 \mu \mathrm{g} / \mathrm{ml})$, the IR of chitosan can be improved by increasing the concentration. However, chitosan and HTCC were dissolved in PBS and the antibacterial effects on the biofilms were much worse than 
those in DDW. It may be speculated that PBS weakened the antibacterial effect by interfering with the electrostatic attraction between the amino groups of chitosan or HTCC and cell membranes. In addition, the resistance of biofilms to drugs was stronger than that in the planktonic state. It has been reported that the resistance of biofilms to antimicrobials, antibodies and phagocytosis is 1,000 times stronger than that of planktonic bacteria (37). It was indicated that in DDW, the anti-biofilm effect of chitosan was stronger than that of HTCC, which was consistent with the planktonic state of E.faecalis. Furthermore, biofilms on dentine blocks were subjected to SEM and broken cells along with debris were observed. The morphology and complement of cells were damaged. According to the quantity of residual bacteria, $78 \mu \mathrm{g} / \mathrm{ml}$ chitosan in DDW also had a better effect.

Due to the potential of application of chitosan and its derivatives in disinfection and obturation of root canals, its biocompatibility was also detected in the present study. The traditional materials in clinical obturation are substances including zinc oxide, resin, calcium hydroxide and glass ionomers. However, nearly each of those materials has certain deficits. For instance, cytotoxicity has been reported for the components of zinc oxide and resin sealers and there is insufficient evidence for the biocompatibility of glass ionomers (40-42). E. faecalis exhibited resistance to calcium hydroxide via a proton pump mechanism (43). Hence, the composition of materials for root canal disinfection and obturation requires further exploration. According to the CCK-8 assay results, chitosan exhibited clear cytotoxicity when the concentration was $>625 \mu \mathrm{g} / \mathrm{ml}$. However, below that concentration, chitosan did not inhibit the proliferation of MC3T3-E1 pre-osteoblasts at 24, 48 and $72 \mathrm{~h}$, and it even promoted the proliferation at certain concentrations. The range of available concentrations for the application of chitosan was expanded while ensuring bactericidal efficacy and biocompatibility. However, HTCC exhibited higher cytotoxicity within the concentration range used in this study and it may be used in the irrigation of root canal disinfection due to its excellent solubility. HTCC has been reported as a component in an injectable thermosensitive hydrogel that may be applied in periodontal therapy and had no acute toxicity even if exhibiting higher cytotoxicity $(44,45)$. Therefore, chitosan and HTCC, both of which have strong antibacterial effects, may be used as alternatives for root canal disinfection and obturation.

In conclusion, chitosan and HTCC have antibacterial effects on E. faecalis in the state of plankton and biofilm. Charge interference reduces the antibiotic efficacy of chitosan and quaternary chitosan on E. faecalis by affecting the electrostatic interaction between amino groups and cell membrane. Chitosan has better biocompatibility, which means it may be used in long-term root canal disinfection and filling. In addition, HTCC may also serve as a new material for the disinfection of root canals.

\section{Acknowledgements}

The authors are grateful to Professor Chengfei Zhang (Comprehensive Dental Care, Faculty of Dentistry, University of Hong Kong, Hong Kong, China), Professor Xiguang Chen
(College of Marine Life Science, Ocean University of China, Qingdao, China) and Dr Min Lin (College of Materials Science and Engineering, Qingdao University, Qingdao, China) for their support by supplying materials and providing technical guidance.

\section{Funding}

The present study was supported by a grant for Young Scientists from The Affiliated Hospital of Qingdao University in Shandong, China (grant no. 2646).

\section{Availability of data and materials}

The datasets used and/or analyzed during the present study are available from the corresponding author on reasonable request.

\section{Authors' contributions}

SW and JD conceived and supervised the present study. NW, YJ, YZ and XW performed the experiments. NW, LM and $\mathrm{HZ}$ analyzed the data. SW and LM provided materials, as well as technical and administrative support. NW and SW wrote and reviewed the manuscript. SW and JD gave the final approval of the version. All authors read and approved the final manuscript.

\section{Ethics approval and consent to participate}

The current study was approved by the Ethics Committee of Qingdao University Health Science Center (Qingdao, China). All the volunteers in this investigation have been provided written informed consents.

\section{Patient consent for publication}

Not applicable.

\section{Competing interests}

The authors declare that they have no competing interests.

\section{References}

1. Fan Z, Qin Y, Liu S, Xing R, Yu H, Chen X, Li K and Li P: Synthesis, characterization, and antifungal evaluation of diethoxyphosphoryl polyaminoethyl chitosan derivatives. Carbohydr Polym 190: 1-11, 2018.

2. Moreno JAS, Mendes AC, Stephansen K, Engwer C, Goycoolea FM, Boisen A, Nielsen LH and Chronakis IS: Development of electrosprayed mucoadhesive chitosan microparticles. Carbohydr Polym 190: 240-247, 2018.

3. Chi J, Jiang Z, Qiao J, Peng Y, Liu W and Han B: Synthesis and anti-metastasis activities of norcantharidin-conjugated carboxymethyl chitosan as a novel drug delivery system. Carbohydr Polym 214: 80-89, 2019.

4. Saravanan S, Vimalraj S, Thanikaivelan P, Banudevi S and Manivasagam G: A review on injectable chitosan/beta glycerophosphate hydrogels for bone tissue regeneration. Int J Biol Macromol 121: 38-54, 2019

5. Palla-Rubio B, Araujo-Gomes N, Fernandez-Gutierrez M, Rojo L, Suay J, Gurruchaga M and Goni I: Synthesis and characterization of silica-chitosan hybrid materials as antibacterial coatings for titanium implants. Carbohydr Polym 203: 331-341, 2019. 
6. Kwak SY, Lew TTS, Sweeney CJ and Koman VB, Wong MH Bohmert-Tatarev K, Snell KD, Seo JS, Chua NH and Strano MS: Chloroplast-selective gene delivery and expression in planta using chitosan-complexed single-walled carbon nanotube carriers. Nat Nanotechnol 14: 447-455, 2019.

7. Carroll EC, Jin L, Mori A, Munoz-Wolf N, Oleszycka E, Moran HBT, Mansouri S, McEntee CP, Lambe E, Agger EM, et al: The vaccine adjuvant chitosan promotes cellular immunity via DNA sensor cGAS-STING-dependent induction of type I interferons. Immunity 44: 597-608, 2016.

8. Chen C, Liu Y, Wang H, Chen G, Wu X, Ren J, Zhang H and Zhao Y: Multifunctional chitosan inverse opal particles for wound healing. ACS Nano 12: 10493-10500, 2018

9. Shariatinia Z: Pharmaceutical applications of chitosan. Adv Colloid Interface Sci 263: 131-194, 2019.

10. Kong M, Chen XG, Xing K and Park HJ: Antimicrobial properties of chitosan and mode of action: A state of the art review. Int J Food Microbiol 144: 51-63, 2010.

11. Shagdarova B, Lunkov A, Il'ina A and Varlamov V: Investigation of the properties of $\mathrm{N}$-[(2-hydroxy-3-trimethylammonium) propyl] chloride chitosan derivatives. Int J Biol Macromol 124 994-1001, 2019.

12. Hoque J, Adhikary U, Yadav V, Samaddar S, Konai MM, Prakash RG, Paramanandham K, Shome BR, Sanyal K and Haldar J: Chitosan derivatives active against multidrug-resistant bacteria and pathogenic fungi: In vivo evaluation as topical antimicrobials. Mol Pharm 13: 3578-3589, 2016.

13. Weiger R, Axmann-Krcmar D and Lost C: Prognosis of conventional root canal treatment reconsidered. Endod Dent Traumatol 14: 1-9, 1998.

14. Sjogren U, Figdor D, Persson S and Sundqvist G: Influence of infection at the time of root filling on the outcome of endodontic treatment of teeth with apical periodontitis. Int Endod J 30: 297-306, 1997.

15. Sundqvist G, Figdor D, Persson S and Sjogren U: Microbiologic analysis of teeth with failed endodontic treatment and the outcome of conservative re-treatment. Oral Surg Oral Med Oral Pathol Oral Radiol Endod 85: 86-93, 1998.

16. Stuart CH, Schwartz SA, Beeson TJ and Owatz CB: Enterococcus faecalis: Its role in root canal treatment failure and current concepts in retreatment. J Endod 32: 93-98, 2006.

17. Rocas IN, Siqueira JF Jr and Santos KR: Association of Enterococcus faecalis with different forms of periradicular diseases. J Endod 30: 315-320, 2004.

18. Zhang C, Du J and Peng Z: Correlation between Enterococcus faecalis and persistent intraradicular infection compared with primary intraradicular infection: A systematic review. J Endod 41: 1207-1213, 2015

19. Sedgley CM,Lennan SL and Appelbe OK: Survival of Enterococcus faecalis in root canals ex vivo. Int Endod J 38: 735-742, 2005.

20. Chen W, Liang J, He Z and Jiang W: Differences in the chemical composition of Enterococcus faecalis biofilm under conditions of starvation and alkalinity. Bioengineered 8: 1-7, 2016.

21. Verlee A, Mincke S and Stevens CV: Recent developments in antibacterial and antifungal chitosan and its derivatives. Carbohydr Polym 164: 268-283, 2017.

22. Cheah WY, Show PL, Ng IS, Lin GY, Chiu CY and Chang YK: Antibacterial activity of quaternized chitosan modified nanofiber membrane. Int J Biol Macromol 126: 569-577, 2019.

23. Conte MC, da Silveira Teixeira C, Bortoluzzi EA, Felippe WT, Dos Santos LGP, Pandolfo MT, da Agostim Cancelier P and da Fonseca Roberti Garcia L: Effect of medicaments used in endodontic regeneration on the morphological characteristics of bovine radicular dentin: Experimental immature tooth model Microsc Res Tech 83: 354-361, 2020.

24. Tonini R, Giovarruscio M, Gorni F, Ionescu A, Brambilla E, Mikhailovna IM, Luzi A, Maciel Pires P and Sauro S: In vitro evaluation of antibacterial properties and smear layer removal/sealer penetration of a novel silver-citrate root canal irrigant. Materials (Basel) 13: E194, 2020.

25. Wang S, Heng BC, Qiu S, Deng J, Shun Pan Cheung G, Jin L, Zhao B and Zhang C: Lipoteichoic acid of Enterococcus faecalis inhibits osteoclastogenesis via transcription factor RBP-J. Innate Immun 25: 13-21, 2019.

26. Wang S, Deng Z, Ye X, Geng X and Zhang C: Enterococcus faecalis attenuates osteogenesis through activation of $\mathrm{p} 38$ and ERK1/2 pathways in MC3T3-E1 cells. Int Endod J 49: 1152-1164, 2016.

27. Zhu X, Wang Q, Zhang C, Cheung GS and Shen Y: Prevalence, phenotype, and genotype of Enterococcus faecalis isolated from saliva and root canals in patients with persistent apical periodontitis. J Endod 36: 1950-1955, 2010
28. Sahariah P, Gaware VS,Lieder R, JonsdottirS,Hjalmarsdottir MA, Sigurjonsson OE and Masson M: The effect of substituent, degree of acetylation and positioning of the cationic charge on the antibacterial activity of quaternary chitosan derivatives. Mar Drugs 12: 4635-4658, 2014.

29. Kravanja G, Primozic M, Knez Z and Leitgeb M: Chitosan-based (Nano)materials for novel biomedical applications. Molecules 24: E1960, 2019.

30. Tan H, Ma R, Lin C, Liu Z and Tang T: Quaternized chitosan as an antimicrobial agent: Antimicrobial activity, mechanism of action and biomedical applications in orthopedics. Int $\mathrm{J} \mathrm{Mol}$ Sci 14: 1854-1869, 2013

31. Chung YC, Su YP, Chen CC, Jia G, Wang HL, Wu JC and Lin JG: Relationship between antibacterial activity of chitosan and surface characteristics of cell wall. Acta Pharmacol Sin 25: 932-936, 2004.

32. Ong TH, Chitra E, Ramamurthy S, Siddalingam RP, Yuen KH, Ambu SP and Davamani F: Chitosan-propolis nanoparticle formulation demonstrates anti-bacterial activity against Enterococcus faecalis biofilms. Plos One 12: e0174888, 2017.

33. Camacho-Alonso F, Julian-Belmonte E, Chiva-Garcia F and Martinez-Beneyto Y: Bactericidal efficacy of photodynamic therapy and chitosan in root canals experimentally infected with Enterococcus faecalis: An in vitro study. Photomed Laser Surg 35: 184-189, 2017.

34. Savitha A, SriRekha A, Vijay R, Ashwija, Champa C and Jaykumar T: An in vivo comparative evaluation of antimicrobial efficacy of chitosan, chlorhexidine gluconate gel and their combination as an intracanal medicament against Enterococcus faecalis in failed endodontic cases using real time polymerase chain reaction (qPCR). Saudi Dent J 31: 360-366, 2019.

35. Loyola-Rodriguez JP, Torres-Mendez F, Espinosa-Cristobal LF, García-Cortes JO,Loyola-Leyva A, GonzálezFJ, Soto-Barreras U, Nieto-Aguilar R and Contreras-Palma G: Antimicrobial activity of endodontic sealers and medications containing chitosan and silver nanoparticles against Enterococcus faecalis. J Appl Biomater Funct Mater 17: 2280800019851771, 2019.

36. Kong M, Chen XG, Liu CS, Liu CG, Meng XH and Yu le J: Antibacterial mechanism of chitosan microspheres in a solid dispersing system against E. coli. Colloids Surf B Biointerfaces 65: 197-202, 2008.

37. Li Y, Chen XG, Liu N, Liu CS, Liu CG, Meng XH, Yu LJ and Kenendy JF: Physicochemical characterization and antibacterial property of chitosan acetates. Carbohydrate Polymers 67: 227-232, 2007.

38. Ji QX, Zhong de Y, Lu R, Zhang WQ, Deng J and Chen XG: In vitro evaluation of the biomedical properties of chitosan and quaternized chitosan for dental applications. Carbohydr Res 344: 1297-1302, 2009.

39. Ma J, Shi H, Sun H, Li J and Bai Y: Antifungal effect of photodynamic therapy mediated by curcumin on Candida albicans biofilms in vitro. Photodiagnosis Photodyn Ther 27: 280-287, 2019.

40. Schwarze T, Leyhausen G and Geurtsen W: Long-term cytocompatibility of various endodontic sealers using a new root canal model. J Endod 28: 749-753, 2002.

41. Troiano G, Perrone D, Dioguardi M, Buonavoglia A, Ardito F and Lo Muzio L: In vitro evaluation of the cytotoxic activity of three epoxy resin-based endodontic sealers. Dent Mater J 37: 374-378, 2018.

42. Patel E, Pradeep P, Kumar P, Choonara YE and Pillay V: Oroactive dental biomaterials and their use in endodontic therapy. J Biomed Mater Res B Appl Biomater 108: 201-212, 2020.

43. Evans M, Davies JK, Sundqvist G and Figdor D: Mechanisms involved in the resistance of Enterococcus faecalis to calcium hydroxide. Int Endod J 35: 221-228, 2002.

44. Ji QX, Chen XG, Zhao QS, Liu CS, Cheng XJ and Wang LC: Injectable thermosensitive hydrogel based on chitosan and quaternized chitosan and the biomedical properties. J Mater Sci Mater Med 20: 1603-1610, 2009.

45. Ji QX, Zhao QS, Deng J and Lu R: A novel injectable chlorhexidine thermosensitive hydrogel for periodontal application: Preparation, antibacterial activity and toxicity evaluation. J Mater Sci Mater Med 21: 2435-2442, 2010.

This work is licensed under a Creative Commons Attribution-NonCommercial-NoDerivatives 4.0 International (CC BY-NC-ND 4.0) License. 